\title{
Targeting a ribonucleoprotein complex containing the caprin-1 protein and the c-Myc mRNA suppresses tumor growth in mice: an identification of a novel oncotarget
}

This article has been corrected. Correction in: Oncotarget. 2019; 10:4919-4919.

\author{
Ya-Qi Qiü,2, Cheng-Wei Yang ${ }^{1}$, Yue-Zhi Lee ${ }^{1}$, Ruey-Bing Yang ${ }^{3}$, Chih-Hao Lee ${ }^{4}$, \\ Hsing-Yu Hsu ${ }^{1}$, Chien-Chung Chang ${ }^{2}$ and Shiow-Ju Lee ${ }^{1}$ \\ ${ }^{1}$ Institute of Biotechnology and Pharmaceutical Research, National Health Research Institutes, Miaoli, Taiwan \\ ${ }^{2}$ Graduate Program of Biotechnology in Medicine, Institute of Molecular \& Cellular Biology, National Tsing Hua University, \\ Hsinchu, Taiwan \\ ${ }^{3}$ Institute of Biomedical Sciences, Academia Sinica, Taipei, Taiwan \\ ${ }^{4}$ Department of Genetics and Complex Diseases, Division of Biological Sciences, Harvard School of Public Health, 665 \\ Huntington Avenue, Boston, Massachusetts, USA
}

Correspondence to: Shiow-Ju Lee, email: slee@nhri.org.tw

Keywords: Caprin-1, C-Myc, Cyclin D, G3BP1, Processing Body

Received: October 02, $2014 \quad$ Accepted: December 09, $2014 \quad$ Published: December 10, 2014

This is an open-access article distributed under the terms of the Creative Commons Attribution License, which permits unrestricted use, distribution, and reproduction in any medium, provided the original author and source are credited.

\section{ABSTRACT}

Tylophorine compounds have been the focus of drug development for decades. Tylophorine derivatives exhibit anti-cancer activities but their cellular targets remain unknown. We used a biotinylated tylophorine derivative to probe for the interacting cellular target(s) of tylophorine. Tylophorine directly binds to caprin-1 and consequently enhances the recruitment of G3BP1, c-Myc mRNA, and cyclin D2 mRNA to form a ribonucleoprotein complex. Subsequently, this tylophorine targeted ribonucleoprotein complex is sequestered to the polysomal fractions and the protein expressions of the associated mRNA-transcripts are repressed. Caprin-1 depleted carcinoma cells become more resistant to tylophorine, associated with decreased formation of the ribonucleoprotein complex targeted by tylophorine. Consequently, tylophorine downregulates C-Myc and cyclins D1/D2, causing hypophosphorylation of $\mathbf{R b}$ and suppression of both processing-body formation and the Warburg effect. Gene expression profiling and gain-of-c-Myc-function experiments also revealed that the downregulated $c-M y c$ contributes to the anti-oncogenic effects of tylophorine compounds. Furthermore, the potent tylophorine derivative dibenzoquinoline-33b elicited a similar effect, as c-Myc protein levels were also decreased in xenograft tumors treated with dibenzoquinoline-33b. Thus, tylophorine compounds exert anticancer activity predominantly by targeting and sequestering the caprin-1 protein and c-Myc mRNA associated ribonucleoprotein complex.

\section{INTRODUCTION}

c-Myc is a transcriptional factor that regulates a variety of cellular processes including the activity of cyclin D-Cdk (cyclin-dependent kinase) [1], the Warburg effect in cancer cell metabolism[2, 3], and cellular mRNP processing [4, 5]. Myc expression is deregulated in a wide range of human cancers and is therefore a therapeutic target. Recently, it was found that the RNA-binding protein human antigen $\mathrm{R}$ inhibits c-Myc expression by recruiting miRNA let-7-loaded RISC (RNA miRNAinduced silencing complex) to the c-Myc 3'UTR [6]. This raises the possibility of developing c-Myc inhibitors by targeting its associated RNP.

Cyclin D (cyclin D1, cyclin D2, and cyclin D3 encoded in human cells) is a member of the cyclin protein family. These proteins are involved in the regulation of cell cycle progression for the transition of G1 to S phase [7]. c-Myc has been shown to regulate transcription of genes involved in cell cycle including cyclin D[1]. The 
retinoblastoma tumor suppressor protein $(\mathrm{pRb})$ is one of the best known substrates of active cyclin D-Cdk4/6 complexes. Thus, the phosphorylated $\mathrm{pRb}$ is a common downstream effector of cyclins D1[8, 9], D2[10, 11], and c-Myc $[1,7]$.

The tumor suppressor protein $\mathrm{pRb}$ is dysregulated in several major cancers. $\mathrm{pRb}$ is a stable protein and is phosphorylated by several Cdks, which downregulates its activity. Active $\mathrm{pRb}$ acts as a tumor suppressor by inhibiting cell cycle progression[7]. In the hypophosphorylated active form, $\mathrm{pRb}$ sequesters the transcriptional factor $\mathrm{E} 2 \mathrm{~F}$. When $\mathrm{pRb}$ is inactivated by hyperphosphorylation, it releases E2F, permitting E2F to execute its cell cycle regulatory functions. Therefore, the hyperphosphorylation of $\mathrm{pRb}$ during late $\mathrm{G} 1$ phase enables the activation of E2F-dependent transcription, e.g cyclin A2[12].

Caprin-1(Cytoplasmic activation- and proliferationassociated protein 1) is ubiquitously expressed, and its phosphorylation is required for normal cell cycle progression from the G1 to S phase. Caprin-1 co-localizes with G3BP1 (Ras GTPase-activating protein-binding protein 1) within the cytoplasmic RNA granules that are associated with microtubules. This caprin-1/G3BP1 complex is thought to regulate the transport and translation of mRNAs whose protein products are involved in proliferation and migration in multiple cell types because the carboxyl-terminal region of caprin-1 selectively binds to c-Myc or cyclin D2 mRNAs[13]. Collectively, the caprin-1, G3BP1, c-Myc mRNA, and Cyclin D2 mRNA complex represents a function-specific RNP complex and is required for important cellular events.

Natural products constitute a successful and promising resource for drug discovery. The elucidation of the cellular targets of therapeutic natural products not only contributes to the identification of valuable novel drug targets for future development, but also guides subsequent molecular pharmacology and mode-of-action studies[14, 16]. Tylophorine-related natural compounds, which are found in the Asclepiadaceae and Moraceae plant families, exhibit multiple biological activities (e.g., anticancer, anti-coronavirus, and anti-inflammatory activities) [17-24]. Tylophorine compounds have been the focus of drug development as therapeutic agents since the 1960s, whereas tylocrebrine failed phase I clinical trials due to neurotoxicity [17]. Although several modes of action for anti-cancer tylophorine compounds have been reported[20, 25-28], their direct cellular target(s) and related pathways remain to be elucidated[24]. In particular, the fundamental mechanisms underlying the broad spectrum, drug-resistant cancer cell inhibitory activities of tylophorine compounds remain to be investigated.

We designed and synthesized a biotinylated tylophorine compound which retained the molecular targeting moiety, enabling the probing of direct cellular target(s). In combination with proteomic approaches and further molecular mechanism studies, the anti-cancer activities of the tylophorine compounds were elucidated. Our results provide a mechanistic basis for developing the tylophorine derived compounds into anti-cancer drugs. The identified cellular target(s) of tylophorine represent novel drug targets for anti-cancer therapeutic applications.

\section{RESULTS}

\section{Synthesis of a biotinylated tylophorine analogue}

Previously, we reported that the non-planar structure between the two major phenanthrene and indolizidine/ quinolizidine moieties, as well as the planarity and rigidity of the indolizidine/quinolizidine moiety of tylophorine compounds, significantly affect the activities of tylophorine analogues[19]. Recently, we successfully synthesized potent tylophorine-derived dibenzoquinolines that elicit the same biological functions as traditional pentacyclic tylophorine compounds[23]. Therefore, we concluded that the angular dibenzoquinoline moiety in tylophorine compounds is responsible for the interactions with their direct target molecule(s). Thus, we sought to design and synthesize a biotinylated tylophorine-derived dibenzoquinoline (Fig. 1A), referred to herein as the "biotinylated tylophorine", to probe direct interacting molecules in cells. The biotinylated tylophorine retained anti-cancer cell activity with $\mathrm{IC}_{50}$ values of $\sim 13-30 \mu \mathrm{M}$ against HONE-1, MCF7, or NUGC-3 carcinoma cells (see Supplemental Table 1).

\section{Identification of direct targets of tylophorine via pull-down experiments with biotinylated tylophorine}

HONE-1 cell lysates were incubated with the vehicle control (dimethyl sulfoxide, DMSO), biotin-X$\mathrm{SSE}$, or biotinylated tylophorine prior to the addition of streptavidin in a pull-down experiment. The pulleddown complex was subjected to sodium dodecyl sulfatepolyacrylamide gel electrophoresis (SDS-PAGE) and silver staining to analyze the proteins that specifically interacted with the biotinylated tylophorine. A total of 6 protein bands were specifically associated with biotinylated tylophorine compared to biotin-X-SSE (Fig. 1B); these bands were excised for further matrix-assisted laser desorption ionization-time of flight (MALDI-TOF) mass spectrometry (MS) proteomics analyses. The potential tylophorine-interacting proteins were identified by Mascot data analysis (Fig. 1C and Supplemental Table 2 ), and the specific interaction of these proteins with biotinylated tylophorine was validated by western blot analysis (Fig. 1D). Caprin-1, $\alpha$-actinin-4, nucleolin, the splicing factor (PSF), polyadenylate-binding protein-1 
(PABP-1), heterogeneous nuclear ribonucleoprotein M3M4 (hnRNPM3-M4), hnRNPQ, TATA-binding proteinassociated factor $2 \mathrm{~N}$ isoform 1 (TAF-15), G3BP1, 40S ribosomal protein S6 (S6), phosphorylated S6 (p-S6), and ribosomal protein $\mathrm{S} 3$ were specifically pulled down by biotinylated tylophorine compared to biotin-X-SSE or DMSO, but the expression levels of these proteins in tylophorine-treated HONE-1 or MCF7 carcinoma cells were not significantly altered compared with DMSOtreated cells, with the exception of p-S6, which was significantly increased (Fig. 1E).

The pull-down of ribosome proteins by biotinylated tylophorine was not unexpected because tylocrebrine was previously reported to inhibit the translocation of peptidyltRNA in ribosomes by $54 \%$, although a tylocrebrine concentration as high as $100 \mu \mathrm{M}$ was used[29]. Because tylophorine compounds exert significant anti-cancer activities, generally with $\mathrm{IC}_{50}$ values ranging from hundreds to a few nM[22-24], we further examined other proteins identified to seek specific targets for anti-cancer.

\section{Tylophorine associates with an RNP complex containing caprin-1, G3BP-1, c-Myc mRNA, and Cyclin D2 mRNA}

Caprin-1 was identified among the molecules that were pulled down by biotinylated tylophorine, and we focused on this protein because it is ubiquitously expressed and required for normal progression through the G1-S phase[13]. We performed co-immunoprecipitation using a caprin- 1 antibody to assess the associated complex members. We identified $\alpha$-actinin-4, G3BP1, and p-S6 within the caprin- 1 complex in the presence of biotinylated tylophorine (Fig. 2A). Because caprin-1 and G3BP1 were previously reported to associate and co-localize within RNA-rich cytoplasmic granules[13], we further dissected the association of c-Myc mRNA and cyclin D2 mRNA in HONE-1 cells by RT-PCR analysis of the products from the pull-down experiment with biotinylated tylophorine (Fig. 2B). We also demonstrated the direct, but weak,

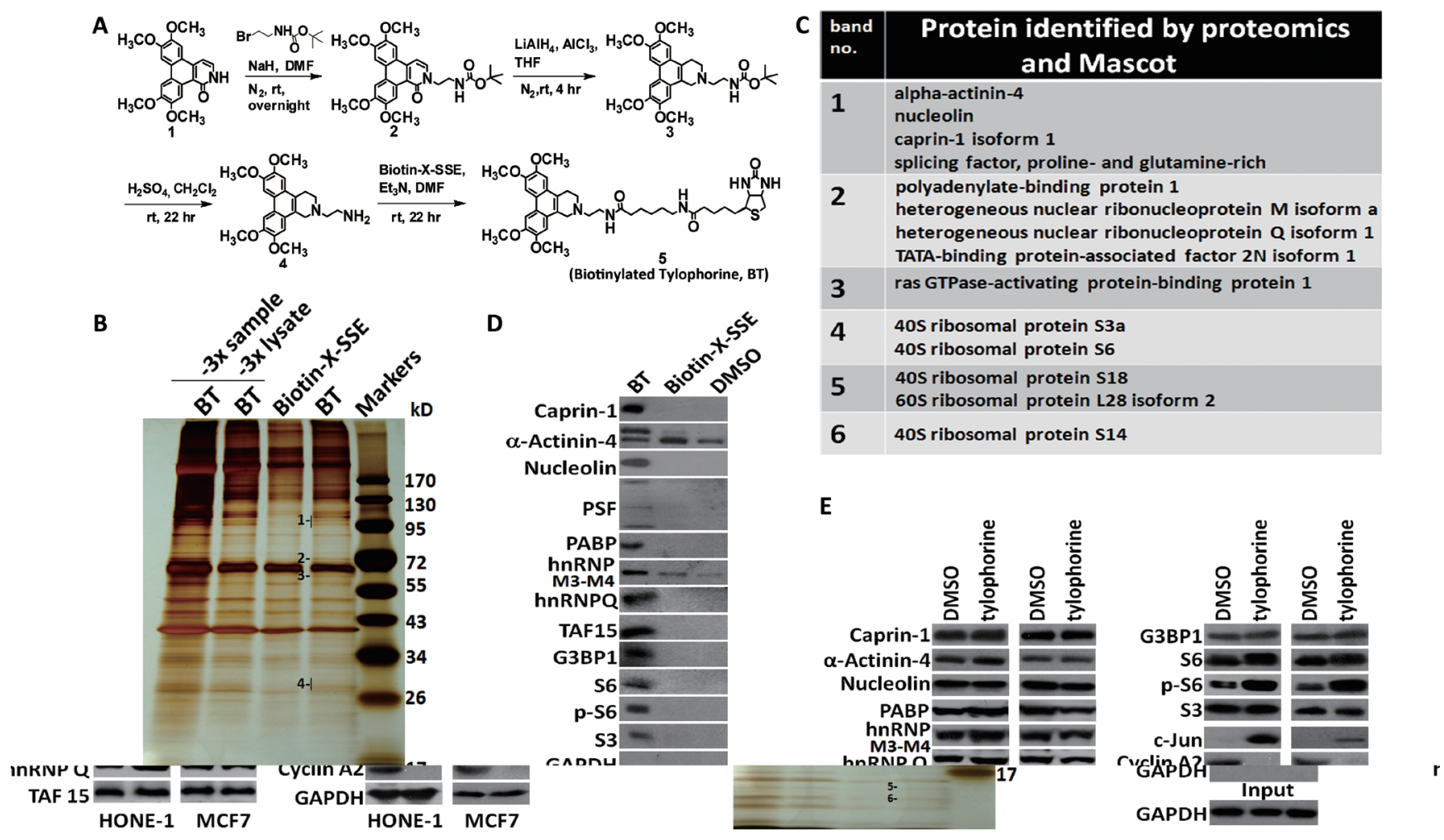

Figure 1: The application of biotinylated tylophorine to probe its direct interacting cellular targets in carcinoma cells. A. Scheme for the synthesis of biotinylated tylophorine (BT), a dibenzoquinoline derivative. B \& C. Pull-down experiment in HONE-1 cell lysates to identify potential molecular targets of tylophorine. BT and biotin-X-SSE were used to pull down the interacting molecules by using streptavidin beads. The lane labelled " $3 \mathrm{x}$ sample" was loaded with 3-fold-amount of the BT pull-down and the lane labelled "3x lysate" was loaded with the BT pull-down from a 3-fold-amount of the lysate. The indicated bands in the silver-stained SDS-PAGE gel (B) were subjected to proteomic studies for Mascot analysis as potential targets (C). D. Immunoblot analyses with the indicated antibodies to confirm the molecules identified by Mascot analysis as potential tylophorine-interacting targets in the pulled-down complexes. E. Immunoblot analysis of the identified intracellular targets of biotinylated tylophorine in the total carcinoma cell lysates of HONE-1 or MCF7 cells treated with tylophorine for $24 \mathrm{~h}$. The downregulation of cyclin A2[20] and upregulation of c-Jun[25] protein expression induced by tylophorine treatment were considered as internal controls in addition to the loading control GAPDH. The results shown are representative of 3 independent experiments. 
interaction of biotinylated tylophorine with caprin-1 in another pull-down experiment using purified recombinant caprin-1 protein (Fig. 2C).

Furthermore, sedimentation fractionation revealed that caprin-1, G3BP1, p-S6, c-Myc mRNA, and cyclin
D2 mRNA co-localized within polysomal fractions upon tylophorine treatment (Fig. 2D-a); this colocalization did not occur in vehicle-treated HONE-1 cells (Fig. 2Db). Moreover, a low abundance of cyclin D2 has been observed in certain carcinoma cell lines[30-32], such as
A

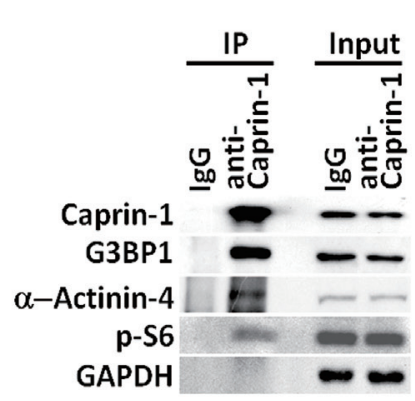

B

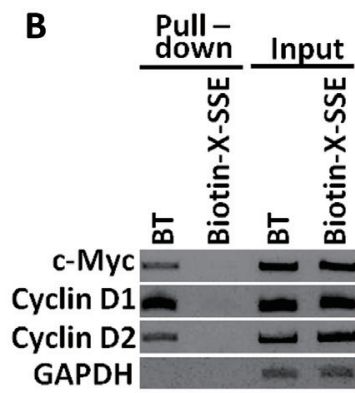

C

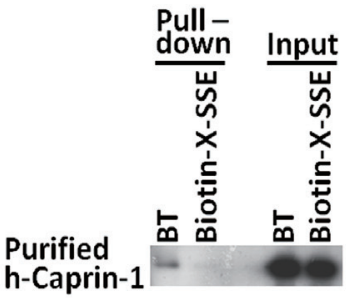

D
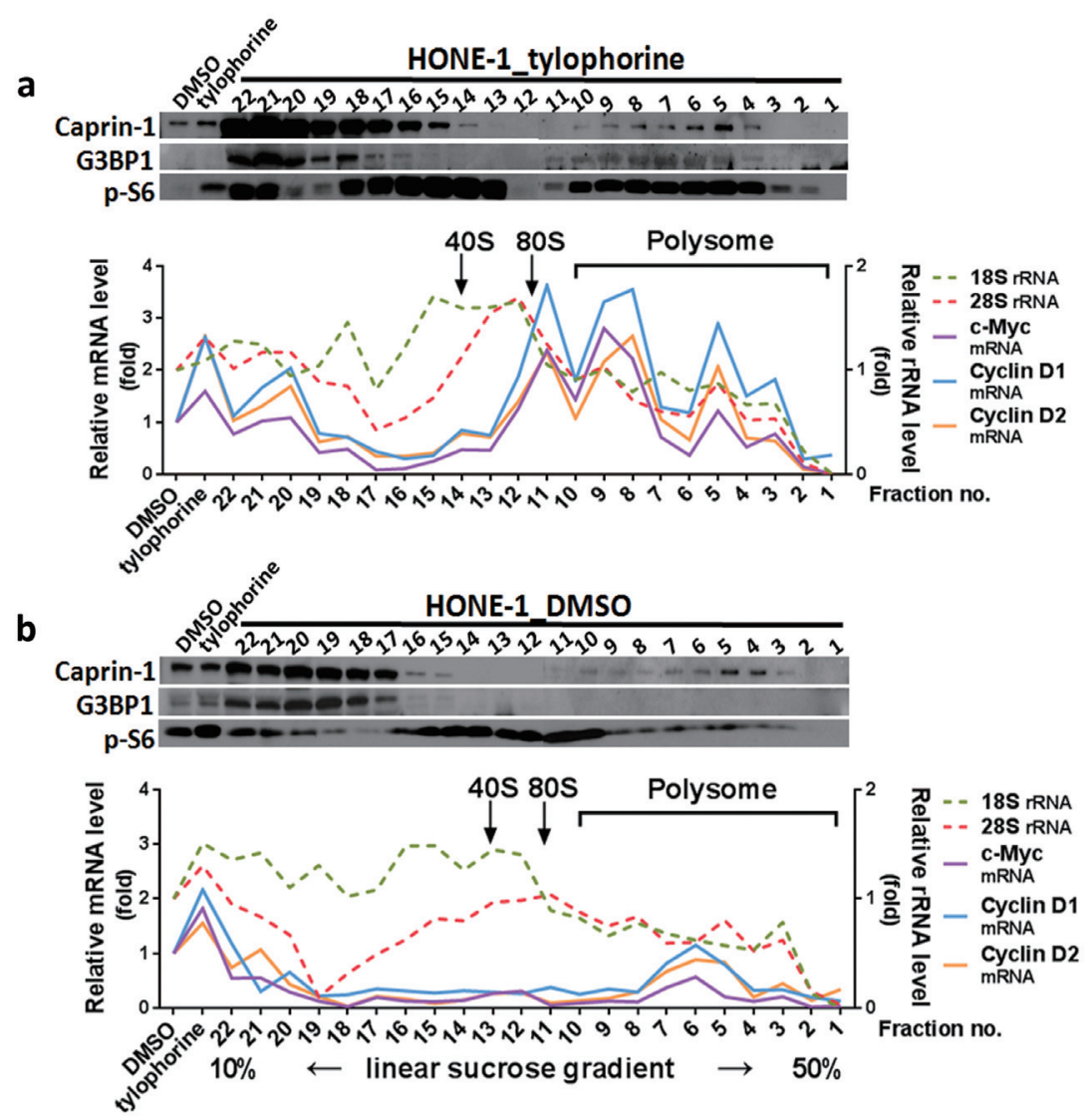

Figure 2: The association of caprin-1 and G3BP1 with c-Myc and cyclins D1/D2 mRNAs through tylophorine. A. The co-immunoprecipitation of caprin-1 with $\alpha$-actinin-4, G3BP1, and p-S6 from the HONE-1 cell lysate in the presence of biotinylated tylophorine was detected by immunoblot analyses with the indicated antibodies. B. Biotinylated tylophorine pulled down the mRNAs for c-Myc and cyclins D1 and D2 from the HONE-1 cell lysate as detected by RT-PCR with the indicated primer pairs. C. Purified recombinant caprin-1 protein physically associates with biotinylated tylophorine. Human caprin-1 was transiently expressed in HEK-293 cells, affinity-purified as described in the Methods section, and applied to a pull-down experiment with biotinylated tylophorine. The protein was subsequently detected by immunoblot analysis using an antibody against human caprin-1. D. Polysome profile analysis (by sucrose gradient sedimentation) and protein (by western, upper panel) and RNA (by qRT-PCR, lower panel) analyses of sucrose gradient fractions for the co-localization of caprin-1, G3BP1, c-Myc mRNA, cyclin D1 mRNA, and cyclin D2 mRNA in the tylophorine-induced RNP complex from the lysates of HONE-1 cells treated with either with tylophorine $(2 \mu \mathrm{M})$ (Fig. 2D-a) or vehicle $(0.1 \%$ DMSO) (Fig. 2D-b) for $24 \mathrm{~h}$. BT, biotinylated tylophorine. The results shown are representative of 3 independent experiments. 
MCF7 (Fig. 3A); under certain conditions, the loss of a specific cyclin can be compensated by the presence of others [33, 34]. Further investigation revealed that cyclin D1 mRNA co-localizes with the caprin-1, G3BP1, and c-Myc mRNA-associated RNP complex (Fig. 2B), as well as within polysomal fractions (Fig. 2D). These results indicate that either cyclin D1 or D2 mRNAs might be sequestered by biotinylated tylophorine (Fig. 2B \& 2D) or associated with a tylophorine-targeted RNP complex in tylophorine-treated HONE-1 cells (Fig. 2D).

\section{Tylophorine represses the protein expression of c-Myc and cyclins D1/D2 but does not decrease their mRNA levels through association with caprin-1}

We examined the effect of tylophorine on the expression of c-Myc and cyclins D1/D2 based on the above pull-down results. Tylophorine treatment increased the mRNA levels of c-Myc and cyclin D1 in both HONE-1 and MCF7 cells. Cyclin D2 mRNA levels were increased only in HONE-1 cells upon tylophorine treatment since cyclin D2 mRNA level was undetectable in MCF7 cells as reported [30-32], regardless of tylophorine treatment (Fig. 3A). However, c-Myc and cyclin D1 protein levels were diminished in HONE-1, MCF7, or NUGC-3 cells upon tylophorine treatment (Fig. 3B). In addition, and as expected, cyclin D2 protein levels were decreased in tylophorine treated HONE-1 and NUGC-3 but no cyclin D2 were detectable in MCF7 cells (Fig. 3B). Furthermore, we used TAMRA to label the newly synthesized protein after tylophorine treatment and followed by immunoprecipitation and western blot to detect the proteins of interest. We found that the de novo protein syntheses of c-Myc and cyclinD1/D2 were diminished upon tylophorine treatment but not that of G3BP1 protein (Fig. 3C). When HONE-1 cells were depleted with caprin-1 by siRNA, the resultant cells became more resistant to tylophorine compounds with an $\sim 2$ fold higher
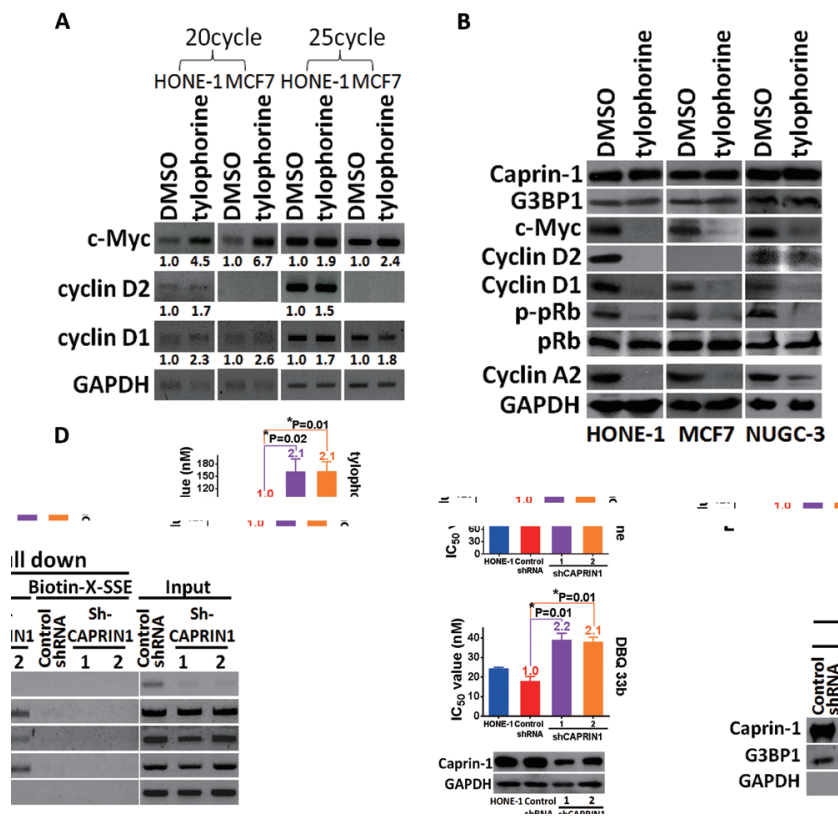

C
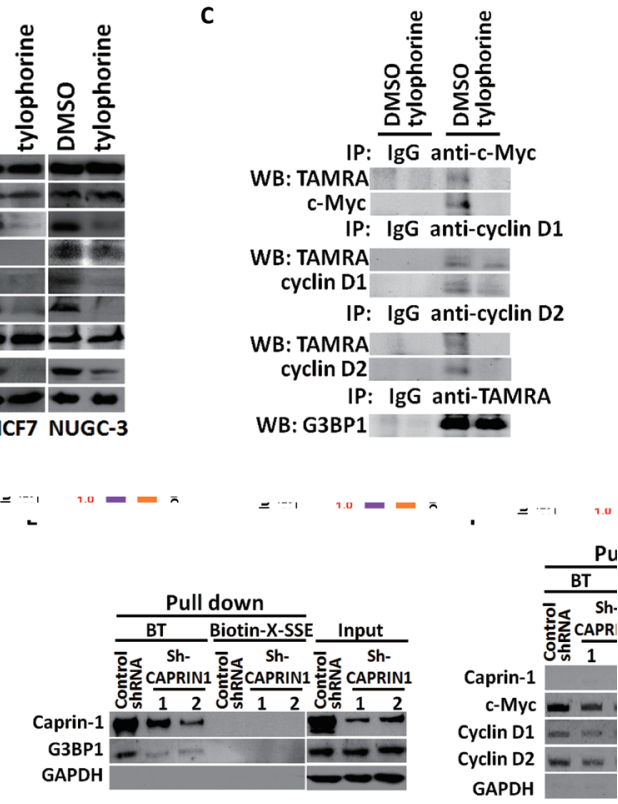

Figure 3: The effect of tylophorine through caprin-1 on c-Myc, cyclin D1, and cyclin D2 expression in carcinoma cells. A. Semi-quantitative RT-PCR analyses of the effect of tylophorine on the mRNA levels of c-Myc, cyclin D1, and cyclin D2. The relative expression levels of each mRNA were normalized with their respective internal loading control GAPDH. B. Immunoblot analyses of the effects of tylophorine on protein expressions related to the caprin-1-associated RNP complex and their common downstream target $\mathrm{pRb}$. The carcinoma cells were treated with tylophorine $(2 \mu \mathrm{M})$ for $24 \mathrm{~h}$ prior to semi-quantitative RT-PCR or western blotting analyses with the indicated gene primer pairs or antibodies. C. Tylophorine repressed the de novo protein syntheses of c-Myc and cyclins D1/D2. TAMRAlabeled newly synthesized proteins from tylophorine treated HONE-1 cells were immunoprecipitated with specific antibody as indicated and then detected by western blotting with indicated antibody. D. Depletion of caprin-1 increased carcinoma cells' resistance to tylophorine or DBQ 33b treatments. HONE-1 cells were transfected with control shRNA or CAPRIN1 shRNA plasmids respectively, and then selected with puromycin. The resultant cells were analyzed by western blotting for validation of caprin-1 depletion before subjected to measurement of cell growth $\mathrm{IC}_{50}$ values by tylophorine or DBQ 33b. A 2-tailed unpaired Student's t test was used to evaluate the p-value between two groups. E \& F. The effect of caprin-1 depletion on the association of tylophorine targeted RNP complex. Caprin-1 depleted HONE-1 lysates described in D were subjected to pull-down assays with biotinylated tylophorine or biotin-X-SSE. Immunoblot (E) and Semi-RT-qPCR analyses (F) were used to detect the protein and mRNA components in the tylophorine-associated RNP complex. The sequences of the gene primer pairs used are listed in Supplemental Table 3. BT, biotinylated tylophorine. The results shown are representative of 3 independent experiments. ${ }^{*}, \mathrm{p}<0.05$. 
$\mathrm{IC}_{50}$ value for tylophorine and its potent derivative DBQ 33b (dibenzoquinoline-33b) (Fig. 3D). Accordingly, the amounts of G3BP1 protein (Fig. 3E) and mRNAs of c-Myc and cyclins D1/D2 pulled down by biotinylated tylophorine were decreased (Fig. 3F).

These results suggest that tylophorine blocked the protein expressions of c-Myc and cyclins D1/D2 through association with caprin-1 thereby downregulating their downstream signaling pathways to exert the anti-cancer activity. The roles of tylophorine-downregulated signaling pathways of c-Myc and cyclins D1/D2 in anti-cancerous tylophorine were investigated as followed.

\section{Tylophorine hypophosphorylates and activates pRb through repressing protein expression of cyclins D1/D2 and c-Myc}

$\mathrm{pRb}$ protein, a common downstream effector of cyclins D1[8, 9] and D2[10, 11] and c-Myc[1, 7], was further examined for tylophorine effects on the anticancer activity. pRb was hypophosphorylated to the active form in tylophorine-treated carcinoma cells, whereas its protein expression levels remained unchanged (Fig. 3B); this result was expected because the protein expressions of the pRb's upstream regulators, cyclins D1[8, 9]/ D2[10, 11] and c-Myc[1, 7], were reduced by tylophorine treatment thereby decreasing the phosphorylation of $\mathrm{pRb}$ (Fig. 3B). Cyclin A2 was downregulated by tylophorine, which partially accounts for the G1 arrest induced by tylophorine[20, 25]. The cyclin A2 promoter region contains two E2F regulatory sites. When either cyclin D2 (Fig. 4A-upper panel) or cyclin D1 (Fig. 4A-lower panel) was overexpressed, the downstream hyperphosphorylation of $\mathrm{pRb}$ resumed, thereby upregulating E2F-mediated cyclin A2 expression[35] in tylophorine-treated cells (Fig. 4A).

Moreover, ectopic overexpression of c-Myc also restored the hyperphosphorylation of the downstream effector $\mathrm{pRb}$ as well as cyclin A2 expression. Strikingly, the expression of cyclins D1/D2 was not restored by ectopic overexpression of c-Myc (Fig. 4B), even though cyclins D1/D2 are downstream target genes of c-Myc signaling [36, 37]. The resulting hyperphosphorylation of $\mathrm{pRb}$ can be, at least in part, attributed to increased levels of cyclin B1[38] (Fig. 4B), a c-Myc target and another upstream effector of $\mathrm{pRb}$, or feedback from upregulated cyclin A2, as ectopic overexpression of cyclin A2 was also able to partially resume the hyperphosphorylation of $\mathrm{pRb}$ (Fig. 4C). These results further emphasize that even ectopically expressed c-Myc can upregulate or stabilize the transcription of cyclins D1 and D2, but their mRNA is subject to sequestration by tylophorine in the caprin-1 and c-Myc mRNA-associated RNP complex, thereby blocking their translation. Therefore, ectopically expressed c-Myc resumed the hyperphosphorylation of $\mathrm{pRb}$ through a pathway independent of cyclins D1/D2.

In summary, active hypophosphorylated $\mathrm{pRb}$ can be inactivated to hyperphosphorylated form upon the overexpression of cyclins D1/D2 or c-Myc in tylophorinetreated carcinoma cells. The hypophosphorylation of $\mathrm{pRb}$ plays an important role in facilitating the anti-cancer activity of tylophorine. Accordingly, the downstream pathway targets of c-Myc as well as those of cyclins D1 and D2 (e.g. pRb, cyclin A2 and cyclin B1) were also downregulated and contributed to the anti-cancer activity of tylophorine.

\section{The effects of tylophorine treatment on cellular events specifically regulated by c-Myc such as the Warburg effect in cancer metabolism and formation of processing bodies}

To demonstrate the functional consequences of c-Myc signaling inhibition by tylophorine, cellular events specifically regulated by c-Myc such as the Warburg effect in cancer metabolism, and formation of processing bodies (P-bodies), were examined.

Although most tylophorine-treated cells were viable, their proliferation was completely suppressed[20], and no significant apoptosis occurred[25]. Therefore, we examined the effect of tylophorine treatment on GLS1 (Glutaminase type 1)[3] and LDHA (Lactate dehydrogenase)[2], c-Myc-targeted genes that mediate the cancer cell nutrient supply via the Warburg effect, and observed that the protein expression levels of these genes were downregulated in tylophorine-treated carcinoma cells (Fig. 5A and 5B). When c-Myc was overexpressed in tylophorine-treated HONE-1 cells, the protein expression levels of GLS1 and LDHA were restored (Fig. 5B). Thus, tylophorine downregulated the Warburg effect by suppressing c-Myc protein expression levels.

The levels of eIF4E $[4,5]$ (a c-Myc target gene) which is involved in cytoplasmic mRNP processing, were significantly reduced in carcinoma cells, as were the levels of Dcp1a, another constituent of P-bodies [39-41](Fig. 5A). We next examined the effects of tylophorine treatment on P-body formation using confocal immunofluorescent microscopy, which indicated that both the numbers of P-bodies and the populations of cells that exhibited P-bodies were dramatically decreased to $0 \sim 5 \%$ upon tylophorine treatment in HONE-1, NUGC-3, or HeLa cells (Fig. 5C).

\section{Tylophorine downregulates c-Myc protein expression levels in carcinoma cells in vitro and in vivo}

Because tylophorine-related alkaloids potently inhibit the growth of a wide variety of drug-sensitive 
A

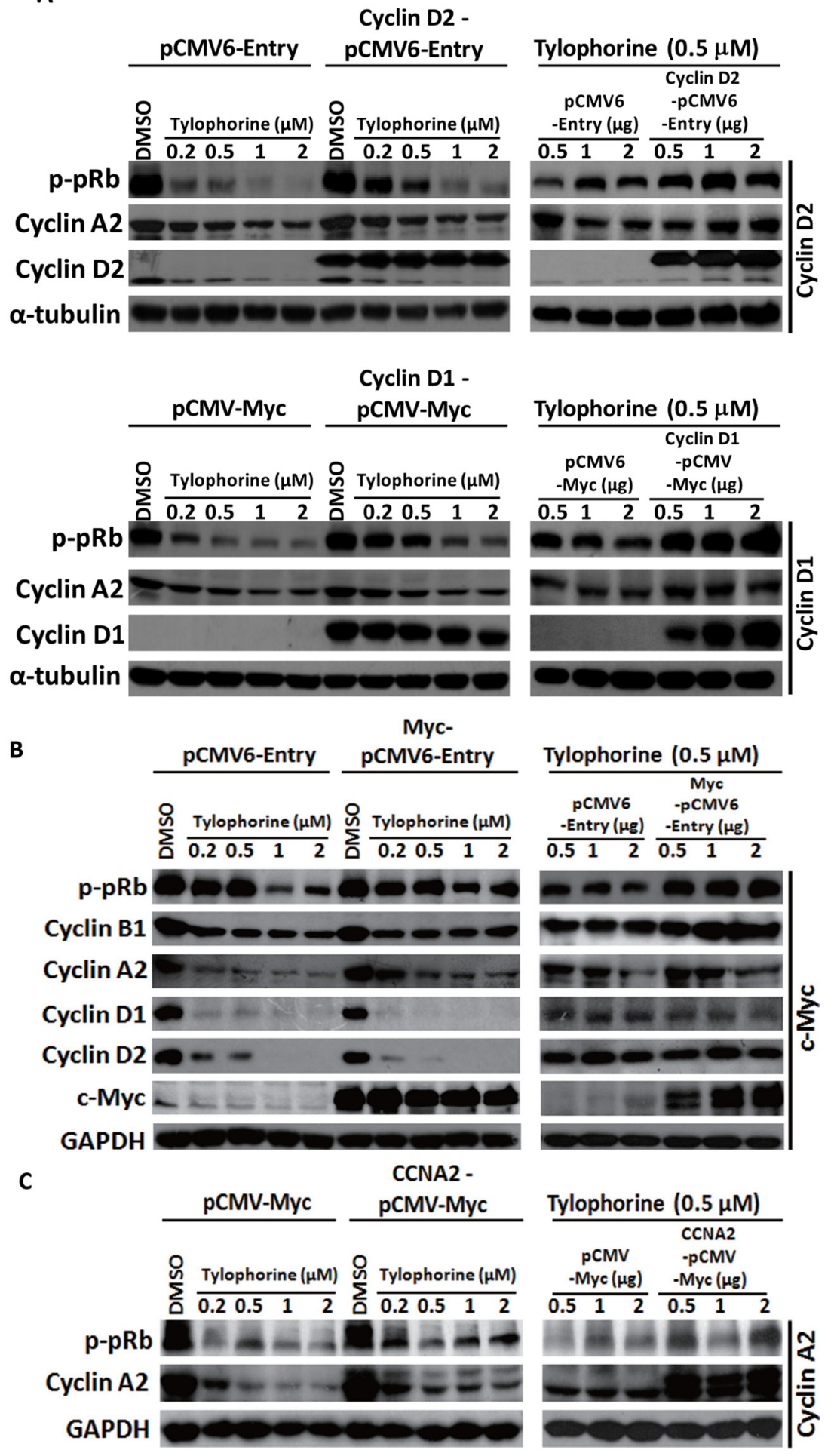

Figure 4: Gain-of-function experiments for tylophorine-induced decreased protein expression of cyclin D1, cyclin D2, and c-Myc. A. Ectopically overexpressed cyclin D1 or D2 restored the hyperphosphorylation of pRb and the expression of cyclin A2. B. Ectopically overexpressed c-Myc rescued the biological function of its downstream effectors (e.g., cyclin B1 and p-pRb) but not the protein expression of cyclin D1 and D2. C. Ectopically overexpressed cyclin A2 moderately restored the hyperphosphorylation of pRb. HONE-1 cells were transfected with the indicated expression vectors for $24 \mathrm{~h}$ prior to treatment with either vehicle (DMSO) or tylophorine at the indicated concentrations for an additional $24 \mathrm{~h}$. The resulting cell lysates were analyzed by western blotting with the indicated antibodies. The relative expression or phosphorylation levels of each protein were normalized with their respective internal loading control $\alpha$-tubulin or GAPDH. The results shown are representative of 3 independent experiments. 


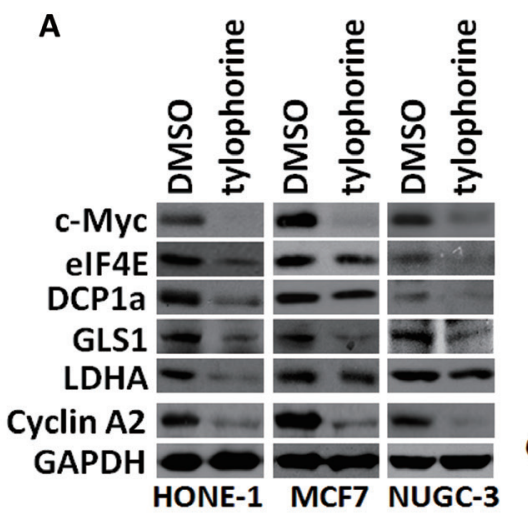

B

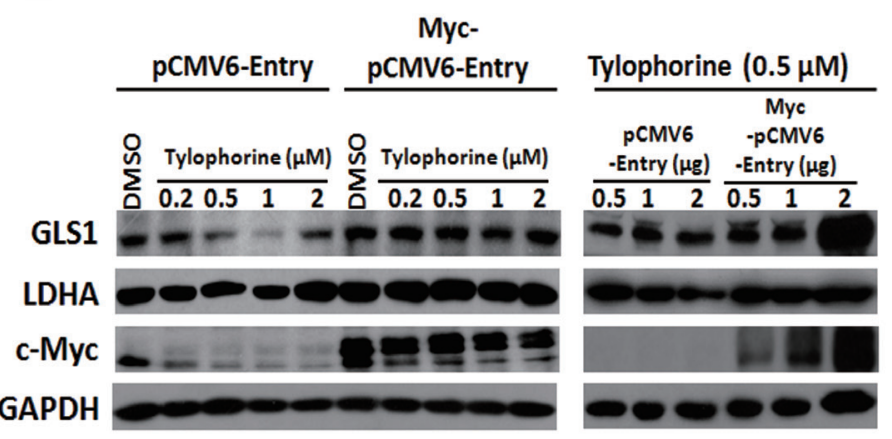

C

NUGC-3

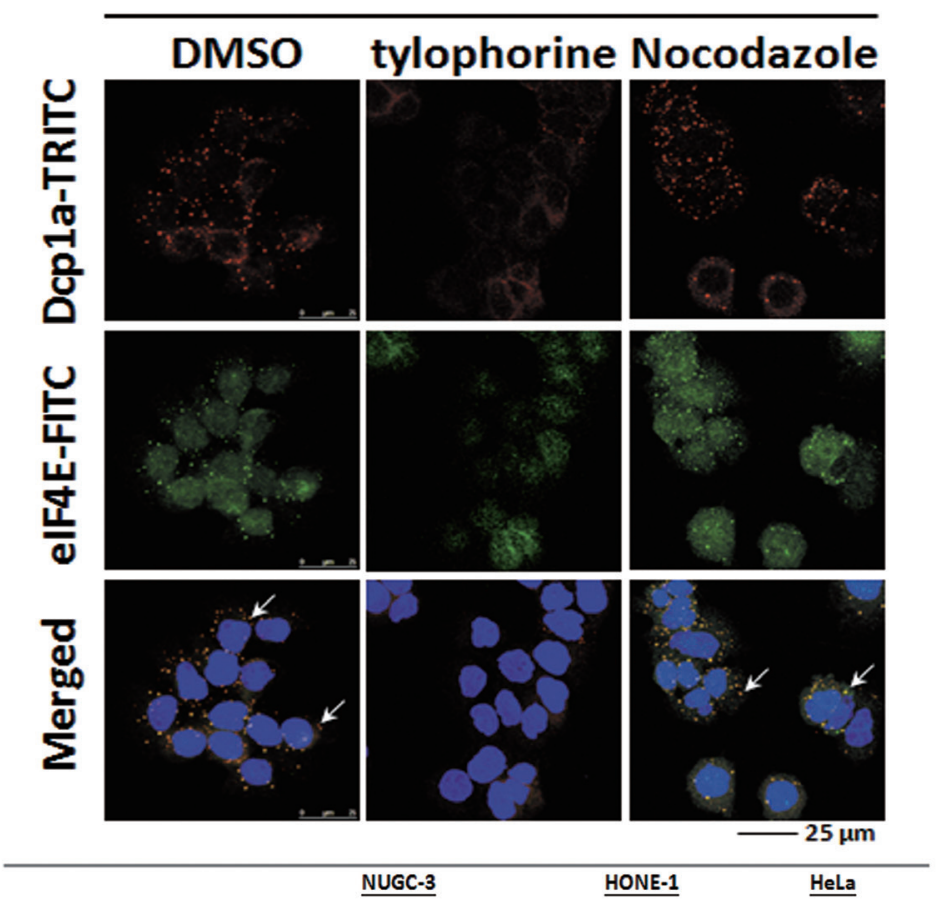

\begin{tabular}{|c|c|c|c|c|c|c|c|}
\hline & \multicolumn{3}{|c|}{ NUGC-3 } & \multicolumn{2}{|c|}{ HONE-1 } & \multicolumn{2}{|c|}{ HeLa } \\
\hline & DMSO & tylophorine & Nocodazole & DMSO & tylophorine & DMSO & tylophorine \\
\hline $\begin{array}{l}\text { Cell population } \\
\text { present } P \text {-bodies } \\
\text { (total cell number } \\
\text { counted) }\end{array}$ & (178) & (174) & (215) & (281) & (153) & $\begin{array}{l}100 \% \\
(70)\end{array}$ & (66) \\
\hline $\begin{array}{c}\text { Relative P-bodies } \\
\text { number/cell } \\
\text { (total P-bodies number) }\end{array}$ & $\begin{array}{l}100 \% \\
(768)\end{array}$ & $\begin{array}{l}5 \% \\
(34)\end{array}$ & $\begin{array}{l}129 \% \\
(1197)\end{array}$ & $\begin{array}{l}100 \% \\
(379)\end{array}$ & $0 \%$ & $\begin{array}{l}100 \% \\
(379)\end{array}$ & $\begin{array}{l}0 \% \\
\text { (0) }\end{array}$ \\
\hline
\end{tabular}

Figure 5: The effects of tylophorine compounds in c-Myc regulated Warburg effect and P-body (processing body) formation. A. Tylophorine treatment decreased the protein expressions of GLS1 and LDHA involved in Warburg effect as well as eIF4E and DCP1a in P-body formation. B Ectopically Overexpressed c-Myc restored the protein expressions of GLS1 and LDHA. The relative expression levels of each protein were normalized with their respective internal control GAPDH. C. Tylophorine treatment decreased the formation of P-bodies. The P-bodies were visualized by immunofluorescent staining using anti-Dcpla-TRITC (in red) and eIF4E-FITC (in green). DAPI (in blue) was used for nuclear counterstaining. The carcinoma cells were treated with DMSO, tylophorine $(2 \mu \mathrm{M})$, or nocodazole $(30 \mathrm{ng} / \mathrm{mL})$ for $24 \mathrm{~h}$ prior to western blotting or immunofluorescent staining analyses with the indicated antibodies. The percentage of the cell population exhibiting P-bodies and the relative percentages of the total number of P-bodies in each treatment were counted with Image-J software (National Institutes of Health) and listed. Nocodazole was used an additional compound control that induces formation of P-bodies. The results shown are representative of 3 independent experiments. 
and drug-resistant cancer cell lines, we evaluated c-Myc protein expression levels in a panel of carcinoma cell lines (13 carcinoma cell lines from 9 types of tumors and 2 fibroblast cell lines) with tylophorine treatment. We observed the sustained blockade of c-Myc protein expression in each of the individual carcinoma cell lines upon treatment with tylophorine or its potent derivative DBQ 33b[23] but not in the fibroblast cell lines. c-Myc protein expression levels were reduced to $1-33 \%$ (Fig. 6A), whereas c-Myc mRNA levels were increased by 1.5-4.5-fold (Figs. 3A, 6B, \& 6C). We also performed gene expression profiling and analysis of the c-Myc downstream pathways that were affected by tylophorine or DBQ 33b(Fig. 6B), as well as validation by RT-qPCR(Fig. 6C). Both compounds increased the expression of c-Myc mRNA by $\sim 2$-4-fold; the mRNA levels of genes that were upregulated by c-Myc were decreased (e.g., cyclin A2, cyclin B1, SERBP1, PRDX3, and POLR3G), and the mRNA levels of genes that were downregulated by c-Myc increased (e.g., GADD45A, and THBS1) (Fig. 6B and 6C). These results are consistent with the above observation that increased c-Myc mRNA levels and decreased c-Myc protein levels occurred in tylophorine-treated cells, which led to negative regulation of c-Myc effector pathways. The genes, whose expression was upregulated or downregulated by tylophorine and DBQ 33b, associated with the function of c-Myc in carcinogenesis are shown in Figure 6D.

In a mouse tumor model using human lung A549 carcinoma xenografts, DBQ $33 \mathrm{~b}$ significantly reduced the tumor volume in a dose-dependent manner[23]. Finally, we examined the c-Myc protein and its mRNA expression in these xenograft tumors[23]. Our results further confirmed reductions in c-Myc protein levels with concomitant increases in its mRNA levels in a dose-dependent manner in the DBQ 33b-treated tumors compared to the vehicletreated tumors (Fig. 6E and 6F). These results correlated with the in vivo anti-tumor activity[23] and in vitro anticancer results for DBQ 33b (Fig. 6A, 6B, \& 6C).

\section{DISCUSSION}

In this study, it was found that tylophorine compounds exert their anti-cancer activities via targeting the caprin-1, G3BP1, c-Myc mRNA, and cyclin D2 or D1 mRNAs containing RNP complex, inhibiting the functions of the RNP components and blocking the protein translation of the corresponding mRNA transcripts (e.g., c-Myc, cyclin D2, and cyclin D1, as well as their downstream pathway components such as pRb) (Fig. 7). Because abnormal c-Myc signaling in cancer cells has been associated with oncogenicity, the downregulation of c-Myc by tylophorine compounds might play a significant role in the anti-cancer activity of these compounds.

The therapeutic targeting of RNP complexes represents an under-explored but emerging strategy for drug discovery[42]. RNPs are ribonucleoproteins in which RNA and protein molecules, such as the ribosome, the enzyme telomerase, hnRNP, small nuclear RNPs (snRNPs), and viral RNP complexes, interact. RNP complexes exhibit multiple roles, dynamic conformations, and chemical instability. Therefore, targeting RNPs for the discovery or development of therapeutic agents remains a challenge. However, several antiviral agents have been reported to target viral RNP complexes with high potency and exhibit significant potential for development into therapeutic drugs [43-45]. To the best of our knowledge, no anti-cancer agent targeting an RNP complex has been reported. We are the first to report that targeting an RNP complex (i.e., targeting the caprin-1 and c-Myc mRNAcontaining RNP complex by tylophorine compounds) in carcinoma cells can efficiently elicit anti-cancer activity.

Significantly, pull-down experiments using biotinylated tylophorine revealed the association of caprin-1, G3BP1, c-Myc mRNA, and cyclins D1/D2 mRNA in untreated carcinoma cell lysates (Fig. 1D and 2B) in which the mRNAs for c-Myc and cyclin D1 and D2 were not upregulated, as was observed in the tylophorinetreated carcinoma cells (Fig. 2D-a). However, we did not observe the polysomal colocalization of G3BP1, c-Myc mRNA, and cyclins D1/D2 mRNA with caprin-1 in the DMSO-treated carcinoma cells by sedimentation fractionation (Fig. 2D-b). Thus, we conclude that the binding of tylophorine to caprin-1 enhanced the recruitment of G3BP1, c-Myc mRNA, and cyclins D1/ D2 mRNA to the RNP complex. This hypothesis was also confirmed by the association of caprin-1 with G3BP1, c-Myc mRNA, and cyclins D1/D2 in polysomal fractions only in tylophorine- but not vehicle-treated carcinoma cells (Fig. 2D), whereas the c-Myc mRNA and cyclins D1/D2 mRNA levels were elevated in tylophorine-treated carcinoma cells (Fig. 2D-a and 3A).

The increased mRNA levels of c-Myc and cyclins D1 and D2 induced upon tylophorine treatment of the carcinoma cells might at least partially reflect an impairment of mRNA degradation due to tylophorine treatment, consistent with the dramatic decrease observed in the number of P-bodies, which suggested a blockade of cellular mRNA degradation processes. Moreover, cytoplasmic mRNAs cycle between polysomes, P-bodies and stress granules and translational repress can occur in these compartments through different mechanisms [46]. In addition to tylophorine treatment dramatically decreased the formation of P-bodies (Fig. 5C), stress granules were nearly not found either in DMSO or tylophorine treated carcinoma cells (Supplemental Figure 1). Using TAMRA to label the newly synthesized protein by tylophorine treatment, we clearly demonstrated that tylophorine repressed the protein expression of c-Myc and cyclins D1/D2 (Fig. 3C). These results further firm that tylophorine sequestered the RNP containing caprin-1 and c-Myc mRNA in the polysomal fractions (Fig. 2D) and 


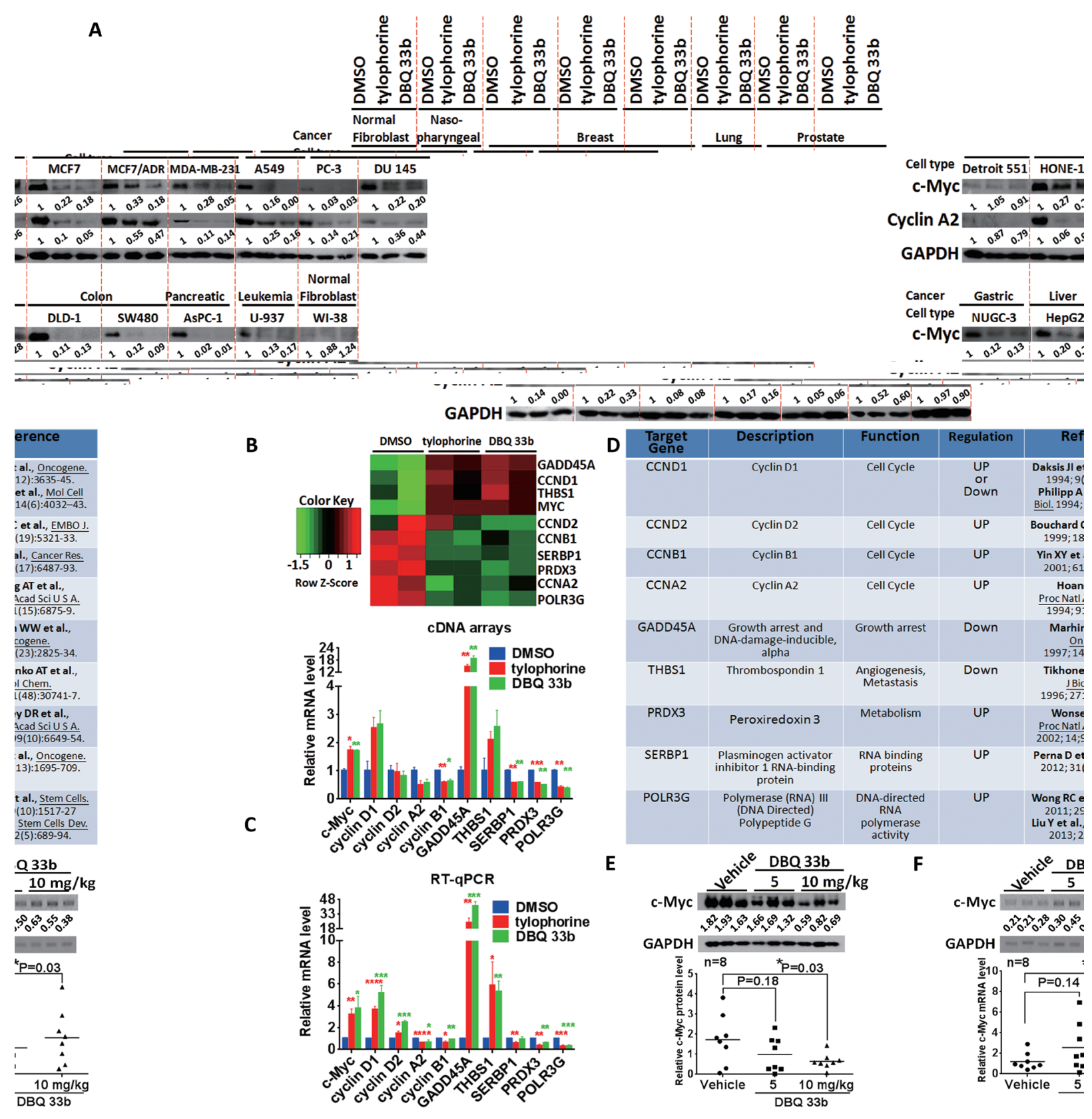

Figure 6: The tylophorine compounds downregulate c-Myc protein levels and affect the expression of c-Myc target genes in carcinoma cells treated with tylophorine compounds in vitro or in vivo. A. Tylophorine and a tylophorine-deriveddibenzoquinoline 33b (DBQ 33b) inhibited the protein expression of c-Myc in 13 carcinoma and 2 fibroblast cell lines. The results shown are representative of 3 independent experiments. B-D. The effects of tylophorine on the expression of c-Myc target genes. The results were obtained from an analysis of gene expression profiling with a cDNA-array (B) and verified by RT-qPCR (C). The genes regulated by the tylophorine compounds through c-Myc are listed by function and their upregulation or downregulation by c-Myc as determined in previous studies as indicated (D). Cells were treated with vehicle $(0.1 \%$ DMSO), tylophorine $(2 \mu \mathrm{M})$, or DBQ $33 \mathrm{~b}(0.5 \mu \mathrm{M})$ for $24 \mathrm{~h}$ prior to lysis for western analysis with the indicated antibodies (A) or prior to mRNA extraction for gene expression profiling using the Illumina-HumanHT-12-v4 Expression-BeadChip (B) and RT-qPCR analysis (C). E \& F. The protein (E) and mRNA (F) expression levels of c-Myc were downregulated in vivo in A549 xenograft tumors in mice by treatment with DBQ 33b[22]. (E) The protein expression of c-Myc detected by immunoblot analysis (upper panel) was quantitated and shown individually (lower panel). (F) The mRNA expression of c-Myc was analyzed by RT-qPCR; the products were shown in the upper panel, and the individual data were plotted in the lower panel. The relative expression levels of mRNA or protein were normalized with their respective internal loading control GAPDH. The sequences of the gene primer pairs used were listed in Supplemental Table 3. *, $\mathrm{p}<0.05 ;{ }^{* *}, \mathrm{p}<0.005 ;{ }^{* * *}, \mathrm{p}<0.0005 ;{ }^{* * * *}, \mathrm{p}<0.0001$. 
blocked the corresponding mRNAs' translation. However, the detailed underlying mechanisms must be carefully addressed and further investigated. Our results suggest that caprin-1 is highly associated with the transport of c-Myc, cyclin D1, and cyclin D2 mRNAs for translation. Thus, the abrogation of this specific biological function of caprin-1 results in the induction of cell cycle arrest at the G1 phase[47].

The expression of c-Myc is elevated in numerous tumor types as the result of multiple mechanisms. c-Myc accumulates at the promoter regions of active genes in carcinoma cells, leading to their abnormal transcriptional amplification and oncogenicity [48]. Therefore, the upregulation of c-Myc is generally associated with tumor aggressiveness and poor clinical outcome. Thus, it is conceivable that the inhibition of c-Myc significantly contributes to the broad-spectrum anti-cancer activity of tylophorine compounds against drug-resistant carcinoma cells. Moreover, the induction of cell cycle arrest at G1[47] by knockdown of caprin-1 suggests that, in addition to the caprin-1 and c-Myc mRNA-associated RNP complex, caprin-1 itself may have favorable potential as a novel anti-cancer drug target.

Ultimately, the blockade of c-Myc mRNA transport by the tylophorine-mediated sequester of the caprin-1, G3BP1, c-Myc mRNA, and cyclin D2 mRNAcontaining RNP complex may contribute significantly to the anti-cancer effects elicited by tylophorine in conjunction with the accumulation of c-Jun[25] (Fig. 7). Tylophorine enhances the c-Jun downregulation of the cyclin A2 promoter activity and results in carcinoma cells dominantly arrested at G1 phase for anti-cancer activity[25]. The ectopically overexpressed c-Myc did not affect the accumulation of c-Jun induced by tylophorine treatment but did increase the expression of cyclin A2 via hyperphosphorylated pRb (Supplemental Figure 2 and Fig. 4B). Thus, we conclude that the elevation of c-Jun levels by tylophorine [23, 25] functions in concert with the targeting of the caprin-1 and c-Myc mRNA-containing RNP complex to produce the anti-cancer activity of tylophorine compounds (Fig. 7).

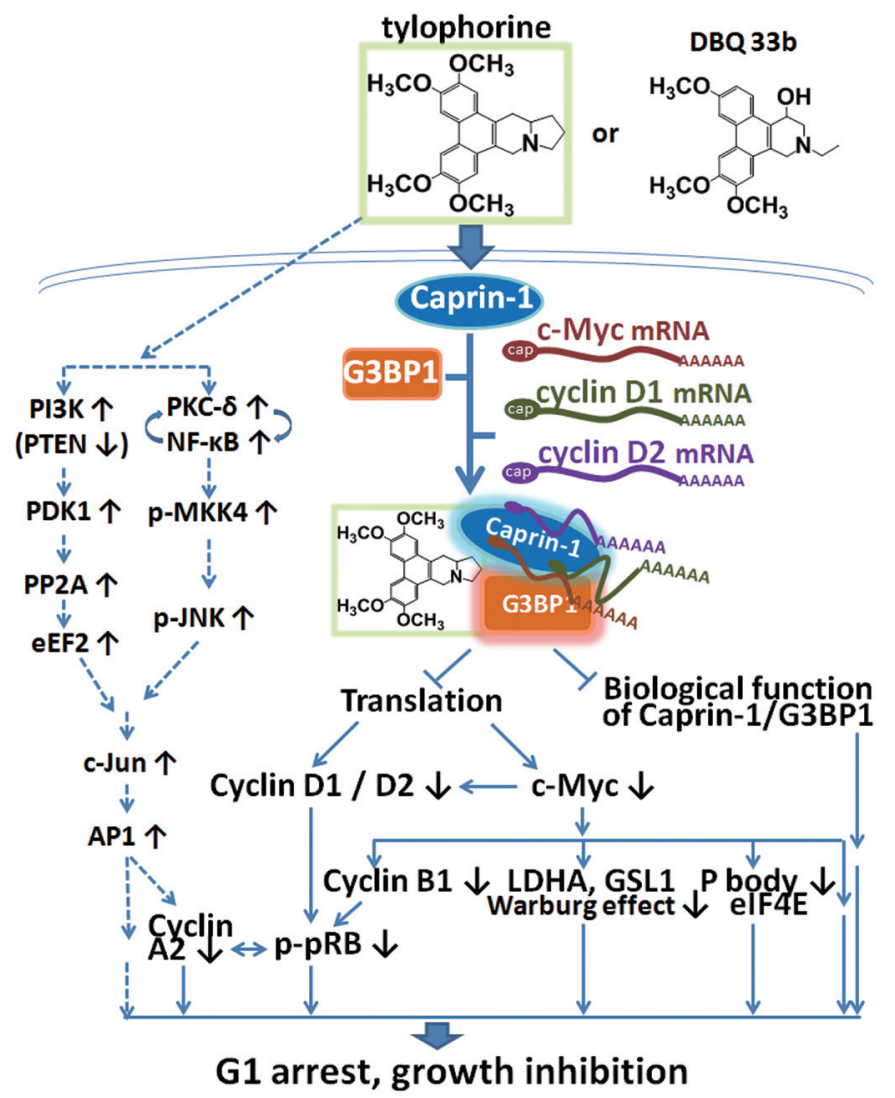

Figure 7: A summary scheme for tylophorine-targeted anti-cancer pathways. The solid lines indicate the direct targeting of tylophorine compounds to caprin-1, c-Myc, and the related pathways. The dashed lines indicate the previously published c-Jun-mediated anti-cancer mechanism of tylophorine[25] including the results shown in Supplemental Figure 2 for decreased PTEN. The elevation of c-Jun by tylophorine compounds is not affected by ectopically overexpressed c-Myc as shown in Supplemental Figure 3 indicating that the tylophorine compounds target the caprin-1 and c-Myc mRNA-containing RNP complexes in parallel with their effects on c-Jun accumulation to elicit anti-cancer activity. 


\section{MATERIALS AND METHODS}

\section{Tylophorine compounds and biotinylated tylophorine (BT)}

Tylophorine and DBQ 33b were prepared as described with a purity greater than $95 \%$ as determined by reverse pahse-HPLC[23]. The scheme for synthesis of biotinylated tylophorine, with purity of $95.87 \%$ analyzed by reverse pahse-HPLC, was shown in Figure 1A (see NMR data below and Supplemental Figure 4).

Compound 1 was prepared as previously described [49] and reacted overnight with a mixture of $\mathrm{NaH}$ and tert-butyl (2-bromoethyl) carbamate in DMF to produce compound 2. We reduced compound 2 with $\mathrm{LiAlH}_{4}$ and $\mathrm{AlCl}_{3}$ (at a 3:1 ratio) in THF at room temperature for $4 \mathrm{~h}$ to produce compound 3 . The $N$-Boc-protected amine was deprotected with $\mathrm{H}_{2} \mathrm{SO}_{4}$ in $\mathrm{CH}_{2} \mathrm{Cl}_{2}$ at room temperature for $22 \mathrm{~h}$ to produce compound 4 . Finally, Biotin-X-SSE (Invitrogen) was coupled to compound 4 using $\mathrm{Et}_{3} \mathrm{~N}$ in $\mathrm{DMF}$ at room temperature for $22 \mathrm{~h}$ to produce compound 5 , the biotinylated tylophorine, a tylophorine-based dibenzoquinoline derivative (Fig. 1A). Compound 5: Yellow crystal; ${ }^{1} \mathrm{H}-\mathrm{NMR}$ (300 MHz, $\mathrm{CD}_{3} \mathrm{OD}$ ): 1.30-1.70 $(12 \mathrm{H}, \mathrm{m}), 2.13(2 \mathrm{H}, \mathrm{t}, J=7.2 \mathrm{~Hz}), 2.24(2 \mathrm{H}, \mathrm{m}), 2.65(1 \mathrm{H}$, d, $J=12.9 \mathrm{~Hz}), 2.85(2 \mathrm{H}, \mathrm{dd}, J=12.9 \mathrm{~Hz}, J=4.8 \mathrm{~Hz}), 2.99$ $(2 \mathrm{H}, \mathrm{d}, J=5.6 \mathrm{~Hz}), 3.11(4 \mathrm{H}, \mathrm{t}, J=7.2 \mathrm{~Hz}), 3.41(2 \mathrm{H}, \mathrm{br} \mathrm{d}$, $J=16.8 \mathrm{~Hz}), 3.69(2 \mathrm{H}, \mathrm{t}, J=5.6 \mathrm{~Hz}), 4.02(3 \mathrm{H}, \mathrm{s}), 4.04(3 \mathrm{H}$, s), $4.08(6 \mathrm{H}, \mathrm{s}), 4.22(1 \mathrm{H}, \mathrm{dd}, J=8.0 \mathrm{~Hz}, J=4.5 \mathrm{~Hz}), 4.41$ $(1 \mathrm{H}, \mathrm{dd}, J=8.0 \mathrm{~Hz}, J=4.5 \mathrm{~Hz}), 4.50(2 \mathrm{H}, \mathrm{s}), 7.20(1 \mathrm{H}, \mathrm{s})$, $7.34(1 \mathrm{H}, \mathrm{s}), 7.93(1 \mathrm{H}, \mathrm{s}), 7.94(1 \mathrm{H}, \mathrm{s}) .{ }^{13} \mathrm{C}-\mathrm{NMR}(500$ $\left.\mathrm{MHz}, \mathrm{CDCl}_{3}\right): 22.3,24.5,25.3,26.1,27.6,27.8,28.3$, 29.6, 34.0, 35.3, 36.0, 38.5, 40.6, 48.6, 51.1, 53.9, 55.6, 56.0, 56.2, 59.7, 61.9, 102.7, 103.2, 103.4, 103.6, 117.7, $122.7,123.8,124.0,124.3,149.2,149.3,149.6,163.7$, 173.6, 175.4. ESI-MS $m / z 758(\mathrm{M}+\mathrm{Na})^{+}$; HRMS calcd for $\mathrm{C}_{39} \mathrm{H}_{53} \mathrm{O}_{7} \mathrm{~N}_{5} \mathrm{NaS}, 758.35579\left(\mathrm{M}^{+}\right)$; found, 758.35592 .

\section{Cell lines and culture}

Two human fibroblast cell lines (Detroit 551 [ATCC CCL-110]; WI-38 [ATCC CCL-75]), the human embryonic kidney cell line (HEK-293[ATCC CRL1573]), and 14 human carcinoma cell lines (breast, MCF7 [ATCC HTB-22], MCF7/ADR [ATCC], MDAMB-231 [BCRC 60425]; cervix, HeLa [BCRC 60005]; colon, DLD-1 [ATCC CCL-221], SW480 [ATCC CCL228]; gastric, NUGC-3 [the Japanese Cancer Research Resources Bank]; leukemia, U-937 [ATCC CRL-1593.2]; liver, HepG2 [ATCC HB-8065]; lung, A549 [ATCC CCL185](obtained from American Type Culture Collection and cultured for passages in fewer than 6 months from initial purchase); nasopharyngeal, HONE-1 [a gift from Dr. Ching-Hwa Tsai at National Taiwan University,
Taiwan, ROC] (short tandem repeat (STR) profile was performed by Bioresource Collection and Research center (BCRC), Taiwan; The DNA profile was unique and no match was found in any known STR database, see data in Supplemental Table 4) ; pancreatic, AsPC-1[BCRC 60494]; and prostate, DU 145 [ATCC HTB-81], PC-3 [BCRC60122]) were used in this study. HEK-293, HeLa, HONE-1, MCF7, MCF7/ADR, HepG2, PC-3, NUGC-3, AsPC-1, Detroit 551, and WI-38 cells were maintained in Dulbecco's Modified Eagle's Medium (DMEM, Hyclone Laboratory Inc.) supplemented with $10 \%$ fetal bovine serum (FBS, Hyclone Laboratory Inc.). DU 145 and U-937 cells were maintained in DMEM-FBS medium supplemented with $1 \mathrm{mM}$ sodium pyruvate (GIBCOLife Technologies). DLD-1, A549, and MDA-MB-231 cells were cultured in RPMI 1640 medium (GIBCO-Life Technologies) supplemented with 10\% FBS, and SW480 cells were maintained in RPMI 1640-FBS medium supplemented with $1 \mathrm{mM}$ sodium pyruvate.

\section{Cell Growth Inhibitory Assays}

HONE-1, caprin-1 silencing HONE-1 cells (3000 cells/well), MCF-7 (6500 cells/well ) and NUGC-3 (4500 cells/well) were seeded into 96-well plates and subjected to measurement of growth inhibition by tylophorine, biotinlylated tylophorine, or DBQ $33 \mathrm{~b}$ and the $\mathrm{IC}_{50}$ values were determined as previously described[18].

\section{Pull-down assay and in-gel digestion}

HONE-1 cell lysates were incubated with biotinylated tylophorine at $4^{\circ} \mathrm{C}$ for $4 \mathrm{~h}$. The biotinylated tylophorine-associated complexes were then pulled down using streptavidin Dynabeads M280 (Invitrogen) at $4{ }^{\circ} \mathrm{C}$ for $1.5 \mathrm{~h}$. The biotinylated tylophorine-bound proteins were eluted with Laemmli buffer and analyzed by electrophoresis on a 4\%-20\% gradient SDS-PAGE gel $(\mathrm{W} / \mathrm{H}: 16 \mathrm{~cm} \mathrm{X} 15 \mathrm{~cm})$ and visualized by silver staining (Amersham Biosciences). The protein bands of interest were excised, subjected to in-gel digestion (see Supplemental Materials and Methods), and analyzed by LC/MS/MS using a Thermo Scientific LTQ XL mass spectrometer (Thermo Scientific). In addition, western blot was used to identify the protein components from the pull-down. The biotinylated tylophorine-bound RNAs were eluted with TRizol Reagent (Invitrogen) and RT-PCR was further used for analyzing the associated components.

\section{Reverse transcription (RT) and quantitative polymerase chain reaction (qPCR)}

The previously described procedure was used[21]. The mRNA expression levels in Figures 2B, 2D, and 3A 
were determined by semi-RT-qPCR, analyzed using the Gel-Pro Analyzer program, and normalized using the housekeeping gene GAPDH when necessary. In Figure 6, the changes in mRNA expression levels were determined using the $\triangle \triangle C T$ method with GAPDH housekeeping genes. The primer pairs used in the PCR reactions are listed in Supplemental Table 3.

\section{Western analyses and co-immunoprecipitation}

We performed western blotting as previously described $[18,20]$ with antibody listed in Supplemental Table 5. See Supplemental Materials and Methods for co-immunoprecipitation using anti-caprin-1 antibody (ProteinTech Group).

\section{Purification of recombinant human caprin-1 expressed in HEK-293 cells}

CAPRIN1-pCMV6-entry was obtained from Origene, and transfected in HEK-293 cells. Expressed caprin-1 was purified using anti-FLAG M2 affinity gel (Sigma-Aldrich). After washes with TBS buffer, the human caprin-1 protein was eluted with $3 \mathrm{X}$ Flag peptide (N-Met-Asp-Tyr-Lys-Asp-His-Asp-Gly-Asp-Tyr-LysAsp-His-Asp-Ile-Asp-Tyr-Lys-Asp-Asp-Asp-Asp-Lys-C, Sigma-Aldrich).

\section{Polysome profile analysis}

HONE-1 cells were treated with $50 \mu \mathrm{g} / \mathrm{ml}$ cycloheximide at $37^{\circ} \mathrm{C}$ for $30 \mathrm{~min}$ before harvest. Total cell lysates were clarified by centrifugation at $4^{\circ} \mathrm{C}$ for 10 min at $13,000 \mathrm{rpm}$. The supernatants were loaded on the top of a $10-50 \%$ sucrose gradient and ultracentrifuged in a SW41Ti Beckman rotor at $4^{\circ} \mathrm{C}$ for $4 \mathrm{~h}$ at $36,000 \mathrm{rpm}$. The fractions were collected from the bottom of the tubes, and the absorbance was measured at a wavelength of 254 nm using an AKTA purifier (GE Healthcare, Amersham Biosciences). RNA and protein were extracted using TRIzol reagent (Invitrogen). Protein expression and mRNA expression were further analyzed by western immunoblot analysis and semi-RT-qPCR, respectively.

\section{TAMRA Labeling and Detection of De Novo Synthesized Proteins of Interest}

HONE-1 cells were washed with PBS and cultured with methionine-free DMEM (GIBCO-Life Technologies) at $37^{\circ} \mathrm{C}$ for $1 \mathrm{~h}$ prior to the addition of $2 \mu \mathrm{M}$ tylophorine and $25 \mu \mathrm{M}$ Click-iT® HPG (L-homopropargylglycine, Invitrogen) and incubation at $37^{\circ} \mathrm{C}$ for $24 \mathrm{~h}$. The cells were then harvested and subjected to the Click Reaction with $20 \mu \mathrm{M}$ TAMRA (Tetramethylrhodamine, Invitrogen) for labeling the de novo synthesized proteins in Click-iT® Protein Reaction Buffer according to the manufacturers' protocol (Invitrogen). The resultant cell lysates were immunoprecipitated with anti-caprin-1 (ProteinTech Group), anti-c-Myc (Cell Signaling Technology), anticyclin D1, anti-cyclin D2 (Santa Cruz Biotechnology), anti-TAMRA (Thermo Scientific) or GAR (Perkin-Elmer) respectively overnight at $4^{\circ} \mathrm{C}$ with constant agitation prior to incubation with protein $\mathrm{G}$ agarose (Millipore) at $4^{\circ} \mathrm{C}$ for another $2 \mathrm{~h}$. After washes, the specific immunoprecipitated protein was eluted and analyzed by western immunoblot analysis with the antibody indicated.

\section{CAPRIN1 Gene Silencing}

HONE-1 cells were transfected with CAPRIN1 shRNA plasmid (TL312677, origene), or scrambled pGFP-C-shLenti shRNA (TR30021, origene) using FuGene $6^{\mathrm{TM}}$ (Roche). At $72 \mathrm{~h}$ post transfection, the cells were cultured in the presence of $1.5 \mathrm{mg} / \mathrm{mL}$ puromycin for selection. In addition, pseudotyped lentivirus containing CAPRIN1 shRNA (clone ID: TRCN0000115975 and TRCN0000115976) or negative control shRNA (shLacZ, clone ID: TRCN72224)(Academia Sinica, Taiwan) were transducted into HONE-1 cells with MOI of 3 in culture medium containing $8 \mu \mathrm{g} / \mathrm{ml}$ polybrene (Millipore). At 24 $\mathrm{h}$ post transduction, the cells were cultured in the presence of $1.5 \mathrm{mg} / \mathrm{mL}$ puromycin for selection.

\section{Transfection}

FuGene $6^{\mathrm{TM}}$ (Roche) was used for transient transfection of the constructs into HONE-1 cells according to the manufacturers' protocols. At $24 \mathrm{~h}$ after transfection, the HONE-1 cells were treated with either the vehicle control $(0.1 \% \mathrm{DMSO})$ or 0.2 to $2 \mu \mathrm{M}$ tylophorine for an additional $24 \mathrm{~h}$. The cells were then harvested in lysis buffer as described above prior to immunoblot analyses.

\section{Plasmid constructs}

The coding regions of human cyclin D1, cyclin D2, and c-Myc were amplified from HONE-1 cDNA using the following primer pairs: 5'-CGGAATTCGGATGGAACACCAGCTCCTGTG-3' \& 5'-CCGCTCGAGTCAGATGTCCACGTCCCG-3' for cyclin D1; 5'-AATGCAGCGATCGCCAT GGAGCTGCTGTGCCACGAGG-3'\&

5'-GTGACGACGCGTCAGGTCGATATCCCGCACGTC TGTA-3, for cyclin D2; and 5'-AATGCAGCGATCGCCCTGGATTTTTTTCGGGTA GTGGAAAACCAGCAGCCTCC-3'\& 5'-GTGACGAC GCGTCGCACAAGAGTTCCGTAGCT GTTCAAGT-3' for c-Myc. The coding regions were next subcloned into 
the EcoRI/XhoI site of pCMV-Myc and the AsiSI/MluI site of pCMV6-Entry to generate the CCND1-pCMVMyc, CCND2-pCMV6-Entry, and MYC-pCMV6-Entry expression vectors. The human CCNA2-pCMV-myc expression vector [20] was amplified from the MGC 132447 clone (Open Biosystems) with primer pairs of 5'-CGAATTCCGATGTTGGGCAACTCTGCG-3' and 5'-GCCTCGAGTTACAGATTTAGTGTCTCTGGTG G-3', then subcloned into EcoRI/XhoI sites of pCMV-myc (Clontech).

\section{Immunofluorescent assay (IFA) and confocal laser scanning microscopy.}

IFA were performed as described previously[21]. We used anti-DCP1a, anti-eIF4E, anti-G3BP1 (Santa Cruz Biotechnology) and anti-PABP (Abcam) antibodies to detect P-bodies and stress granules. Fluorescence imaging was performed using a Leica TSC SP5 laser-scanning confocal microscope.

\section{Protein extraction from xenografted murine tumors}

The xenografted murine tumor tissues [23] were flash-frozen in liquid nitrogen, washed with ice-cold PBS, and homogenized using a TissueLyser II (Qiagen) according to the manufacturer's protocols. Total protein was extracted in lysis buffer as detailed above and further analyzed by western blotting. Total RNA was extracted using TRIzol Reagent (Invitrogen), reverse transcribed using Superscript III (Invitrogen), and analyzed by realtime RT-qPCR as described above.

\section{Gene expression profiling using cDNA arrays}

HONE-1 cells were treated with the vehicle control (0.1\% DMSO), $0.5 \mu \mathrm{M}$ DBQ $33 \mathrm{~b}$, or $2 \mu \mathrm{M}$ tylophorine. After treatment with the compounds for $24 \mathrm{~h}$, total RNA was extracted using TRIzol reagent (Invitrogen), and expression profiling of the coding genes performed using the Illumina Human HT-12 v4 Expression BeadChip. Furthermore, the gene expression data from the Illumina arrays were validated by real-time RT-qPCR.

\section{CONFLICT OF INTEREST}

The authors declare no conflict of interest.

\section{ACKNOWLEDGEMENTS}

This work was funded by the National Science Council of Taiwan (NSC 102-2628-B-400-002-MY3), the National Health Research Institutes, Taiwan, R.O.C., and the Ministry of Economic Affairs, R.O.C. "102-EC17-A-02-04-1099” \& “103-EC-17-A-22-1099”. Y-Q Qiu is currently a $\mathrm{PhD}$ student in the Graduate Program of Biotechnology in Medicine, which is sponsored by the National Health Research Institutes and National Tsing Hua University. We would like to acknowledge the NHRI Optical Biology Core Facility for their assistance with confocal microscopy..

\section{REFERENCES}

1. Mateyak MK, Obaya AJ and Sedivy JM. c-Myc regulates cyclin D-Cdk4 and -Cdk6 activity but affects cell cycle progression at multiple independent points. Molecular and cellular biology. 1999; 19(7):4672-4683.

2. Dang CV, Le A and Gao P. MYC-induced cancer cell energy metabolism and therapeutic opportunities. Clinical cancer research. 2009; 15(21):6479-6483.

3. Gao P, Tchernyshyov I, Chang TC, Lee YS, Kita K, Ochi T, Zeller KI, De Marzo AM, Van Eyk JE, Mendell JT and Dang CV. c-Myc suppression of miR-23a/b enhances mitochondrial glutaminase expression and glutamine metabolism. Nature. 2009; 458(7239):762-765.

4. Jones RM, Branda J, Johnston KA, Polymenis M, Gadd M, Rustgi A, Callanan L and Schmidt EV. An essential E box in the promoter of the gene encoding the mRNA capbinding protein (eukaryotic initiation factor 4E) is a target for activation by c-myc. Molecular and cellular biology. 1996; 16(9):4754-4764.

5. Labisso WL, Wirth M, Stojanovic N, Stauber RH, Schnieke A, Schmid RM, Kramer OH, Saur D and Schneider G. MYC directs transcription of MCL1 and eIF4E genes to control sensitivity of gastric cancer cells toward HDAC inhibitors. Cell cycle. 2012; 11(8):1593-1602.

6. Kim HH, Kuwano Y, Srikantan S, Lee EK, Martindale JL and Gorospe M. HuR recruits let-7/RISC to repress c-Myc expression. Genes \& development. 2009; 23(15):17431748.

7. Adams PD. Regulation of the retinoblastoma tumor suppressor protein by cyclin/cdks. Biochimica et biophysica acta. 2001; 1471(3):M123-133.

8. Paternot S, Arsenijevic T, Coulonval K, Bockstaele L, Dumont JE and Roger PP. Distinct specificities of $\mathrm{pRb}$ phosphorylation by CDK4 activated by cyclin D1 or cyclin D3: differential involvement in the distinct mitogenic modes of thyroid epithelial cells. Cell cycle. 2006; 5(1):6170.

9. Tashiro E, Maruki H, Minato Y, Doki Y, Weinstein IB and Imoto M. Overexpression of cyclin D1 contributes to malignancy by up-regulation of fibroblast growth factor receptor 1 via the $\mathrm{pRB} / \mathrm{E} 2 \mathrm{~F}$ pathway. Cancer research. 2003; 63(2):424-431.

10. Sweeney KJ, Sarcevic B, Sutherland RL and Musgrove EA. 
Cyclin D2 activates Cdk2 in preference to Cdk4 in human breast epithelial cells. Oncogene. 1997; 14(11):1329-1340.

11. Arvanitakis L, Yaseen $\mathrm{N}$ and Sharma S. Latent membrane protein-1 induces cyclin D2 expression, $\mathrm{pRb}$ hyperphosphorylation, and loss of TGF-beta 1-mediated growth inhibition in EBV-positive B cells. The Journal of Immunology. 1995; 155(3):1047-1056.

12. Seville LL, Shah N, Westwell AD and Chan WC. Modulation of $\mathrm{pRB} / \mathrm{E} 2 \mathrm{~F}$ functions in the regulation of cell cycle and in cancer. Current cancer drug targets. 2005; 5(3):159-170.

13. Solomon S, Xu Y, Wang B, David MD, Schubert P, Kennedy D and Schrader JW. Distinct structural features of caprin-1 mediate its interaction with G3BP-1 and its induction of phosphorylation of eukaryotic translation initiation factor 2alpha, entry to cytoplasmic stress granules, and selective interaction with a subset of mRNAs. Molecular and cellular biology. 2007; 27(6):2324-2342.

14. Harvey AL. Natural products in drug discovery. Drug discovery today. 2008; 13(19-20):894-901.

15. Gu J, Gui Y, Chen L, Yuan G, Lu HZ and Xu X. Use of natural products as chemical library for drug discovery and network pharmacology. PloS one. 2013; 8(4):e62839.

16. Lee YZ, Yang CW, Chang HY, Hsu HY, Chen IS, Chang HS, Lee CH, Lee JC, Kumar CR, Qui YQ, Chao YS and Lee SJ. Discovery of selective inhibitors of Glutaminase-2, which inhibit mTORC1, activate autophagy and inhibit proliferation in cancer cells. Oncotarget .2014;5(15):60876101 .

17. Suffness M and Douros J. (1980). Anticancer agents based on natural product models: Academic Press).

18. Yang CW, Chen WL, Wu PL, Tseng HY and Lee SJ. Anti-inflammatory mechanisms of phenanthroindolizidine alkaloids. Molecular pharmacology. 2006; 69(3):749-758.

19. Yang CW, Chuang TH, Wu PL, Huang WH and Lee SJ. Anti-inflammatory effects of 7-methoxycryptopleurine and structure-activity relations of phenanthroindolizidines and phenanthroquinolizidines. Biochemical and biophysical research communications. 2007; 354(4):942-948.

20. Wu CM, Yang CW, Lee YZ, Chuang TH, Wu PL, Chao YS and Lee SJ. Tylophorine arrests carcinoma cells at G1 phase by downregulating cyclin A2 expression. Biochemical and biophysical research communications. 2009; 386(1):140145.

21. Yang CW, Lee YZ, Kang IJ, Barnard DL, Jan JT, Lin D, Huang CW, Yeh TK, Chao YS and Lee SJ. Identification of phenanthroindolizines and phenanthroquinolizidines as novel potent anti-coronaviral agents for porcine enteropathogenic coronavirus transmissible gastroenteritis virus and human severe acute respiratory syndrome coronavirus. Antiviral research. 2010; 88(2):160-168.

22. Lee YZ, Huang CW, Yang CW, Hsu HY, Kang IJ, Chao YS, Chen IS, Chang HY and Lee SJ. Isolation and biological activities of phenanthroindolizidine and septicine alkaloids from the Formosan Tylophora ovata. Planta medica. 2011; 77(17):1932-1938.

23. Lee YZ, Yang CW, Hsu HY, Qiu YQ, Yeh TK, Chang HY, Chao YS and Lee SJ. Synthesis and biological evaluation of tylophorine-derived dibenzoquinolines as orally active agents: exploration of the role of tylophorine e ring on biological activity. Journal of medicinal chemistry. 2012; 55(23):10363-10377.

24. Chemler SR. Phenanthroindolizidines and Phenanthroquinolizidines: Promising Alkaloids for AntiCancer Therapy. Current bioactive compounds. 2009; 5(1):2-19.

25. Yang CW, Lee YZ, Hsu HY, Wu CM, Chang HY, Chao YS and Lee SJ. c-Jun-mediated anticancer mechanisms of tylophorine. Carcinogenesis. 2013; 34:1304-1314.

26. Gao W, Lam W, Zhong S, Kaczmarek C, Baker DC and Cheng YC. Novel mode of action of tylophorine analogs as antitumor compounds. Cancer research. 2004; 64(2):678688.

27. Meng X, Zhang Y, Jia Z, Huo X, He X, Tian G, Wu M, Wang Z, Zhou X, Xiong S, Gao X, Wu Z, Han J, et al. A novel tylophorine analog W-8 up-regulates forkhead boxP3 expression and ameliorates murine colitis. Journal of leukocyte biology. 2013; 93(1):83-93.

28. Yang X, Shi Q, Lai CY, Chen CY, Ohkoshi E, Yang SC, Wang CY, Bastow KF, Wu TS, Pan SL, Teng CM, Yang $\mathrm{PC}$ and Lee KH. Antitumor agents 295. E-ring hydroxylated antofine and cryptopleurine analogues as antiproliferative agents: design, synthesis, and mechanistic studies. Journal of medicinal chemistry. 2012; 55(15):6751-6761.

29. Huang MT and Grollman AP. Mode of action of tylocrebrine: effects on protein and nucleic acid synthesis. Molecular pharmacology. 1972; 8(5):538-550.

30. Zhou Q, Stetler-Stevenson M and Steeg PS. Inhibition of cyclin D expression in human breast carcinoma cells by retinoids in vitro. Oncogene. 1997; 15(1):107-115.

31. Parker BS, Cutts SM, Nudelman A, Rephaeli A, Phillips DR and Sukumar S. Mitoxantrone mediates demethylation and reexpression of cyclin $\mathrm{d} 2$, estrogen receptor and 14.3.3sigma in breast cancer cells. Cancer biology \& therapy. 2003; 2(3):259-263.

32. Evron E, Umbricht CB, Korz D, Raman V, Loeb DM, Niranjan B, Buluwela L, Weitzman SA, Marks $\mathrm{J}$ and Sukumar S. Loss of cyclin D2 expression in the majority of breast cancers is associated with promoter hypermethylation. Cancer research. 2001; 61(6):2782-2787.

33. Bowe DB, Kenney NJ, Adereth Y and Maroulakou IG. Suppression of Neu-induced mammary tumor growth in cyclin D1 deficient mice is compensated for by cyclin E. Oncogene. 2002; 21(2):291-298.

34. Lam EW, Glassford J, Banerji L, Thomas NS, Sicinski P and Klaus GG. Cyclin D3 compensates for loss of cyclin D2 in mouse B-lymphocytes activated via the antigen receptor and CD40. The Journal of biological chemistry. 2000; 
275(5):3479-3484.

35. Blanchard JM. Cyclin A2 transcriptional regulation: modulation of cell cycle control at the G1/S transition by peripheral cues. Biochemical pharmacology. 2000; 60(8):1179-1184.

36. Daksis JI, Lu RY, Facchini LM, Marhin WW and Penn LJ. Myc induces cyclin D1 expression in the absence of de novo protein synthesis and links mitogen-stimulated signal transduction to the cell cycle. Oncogene. 1994; 9(12):36353645.

37. Perez-Roger I, Kim SH, Griffiths B, Sewing A and Land H. Cyclins D1 and D2 mediate myc-induced proliferation via sequestration of p27(Kip1) and p21(Cip1). The EMBO journal. 1999; 18(19):5310-5320.

38. Seo HR, Kim J, Bae S, Soh JW and Lee YS. Cdk5mediated phosphorylation of c-Myc on Ser-62 is essential in transcriptional activation of cyclin B1 by cyclin G1. The Journal of biological chemistry. 2008; 283(23):1560115610 .

39. Kedersha N, Tisdale S, Hickman T and Anderson P. Realtime and quantitative imaging of mammalian stress granules and processing bodies. Methods in enzymology. 2008; 448:521-552.

40. Lee HC, Cho H and Kim YK. Ectopic expression of eIF4Etransporter triggers the movement of eIF4E into P-bodies, inhibiting steady-state translation but not the pioneer round of translation. Biochemical and biophysical research communications. 2008; 369(4):1160-1165.

41. Kedersha N, Stoecklin G, Ayodele M, Yacono P, LykkeAndersen J, Fritzler MJ, Scheuner D, Kaufman RJ, Golan $\mathrm{DE}$ and Anderson P. Stress granules and processing bodies are dynamically linked sites of mRNP remodeling. The Journal of cell biology. 2005; 169(6):871-884.
42. DeJong ES, Luy B and Marino JP. RNA and RNA-protein complexes as targets for therapeutic intervention. Current topics in medicinal chemistry. 2002; 2(3):289-302.

43. Zhang $\mathrm{W}, \mathrm{Du} \mathrm{J}, \mathrm{Yu} \mathrm{K}$, Wang $\mathrm{T}$, Yong $\mathrm{X}$ and $\mathrm{Yu} \mathrm{XF}$. Association of potent human antiviral cytidine deaminases with 7SL RNA and viral RNP in HIV-1 virions. Journal of virology. 2010; 84(24):12903-12913.

44. Amorim MJ, Kao RY and Digard P. Nucleozin targets cytoplasmic trafficking of viral ribonucleoprotein-Rab11 complexes in influenza A virus infection. Journal of virology. 2013; 87(8):4694-4703.

45. He J, Qi WB, Wang L, Tian J, Jiao PR, Liu GQ, Ye WC and Liao M. Amaryllidaceae alkaloids inhibit nuclear-tocytoplasmic export of ribonucleoprotein (RNP) complex of highly pathogenic avian influenza virus H5N1. Influenza and other respiratory viruses. 2013; 7(6):922-931.

46. Balagopal V and Parker R. Polysomes, P bodies and stress granules: states and fates of eukaryotic mRNAs. Current opinion in cell biology. 2009; 21(3):403-408.

47. Wang B, David MD and Schrader JW. Absence of caprin-1 results in defects in cellular proliferation. The Journal of Immunology. 2005; 175(7):4274-4282.

48. Lin CY, Loven J, Rahl PB, Paranal RM, Burge CB, Bradner JE, Lee TI and Young RA. Transcriptional amplification in tumor cells with elevated c-Myc. Cell. 2012; 151(1):56-67.

49. Chuang TH, Lee SJ, Yang CW and Wu PL. Expedient synthesis and structure-activity relationships of phenanthroindolizidine and phenanthroquinolizidine alkaloids. Organic \& biomolecular chemistry. 2006; 4(5):860-867. 